\title{
Salt, hypertension and renal disease: comparative medicine, models and real diseases
}

\author{
A.R. Michell \\ Professor of Applied Physiology and Comparative Medicine, Royal Veterinary College, University of \\ London, UK
}

\begin{abstract}
Summary: Dogs are well established as experimental animals for the study of both renal disease and hypertension, but most work is based on surgical or pharmacological models and relatively little on spontaneous diseases. This review argues for the latter as an underexploited aspect of comparative medicine. The most important feature of canine hypertension may not be the ease with which models can be produced but the fact that dogs are actually rather resistant to hypertension, and perhaps to its effects, even when they have chronic renal failure. The importance of natural models of chronic renal failure is strengthened by the evidence that self-sustaining progression is a consequence of extreme nephron loss, that is, a late event, rather than the dominant feature of the course of the disease.

The role of salt in hypertension is discussed and emphasis given to the importance of understanding the physiological basis of nutritional requirement and recognizing that it is unlikely to exceed $0.6 \mathrm{mmol} / \mathrm{kg} /$ day for most healthy adult mammals except during pregnancy or lactation. Such a perspective is essential to the evaluation of experiments, whether in animals or humans, in order to avoid arbitrary definitions of 'high' or 'low' sodium intake, and the serious misinterpretations of data which result. An age-related rise in arterial pressure may well be a warning of excess salt intake, rather than a normal occurrence. Problems of defining hypertension in the face of variability of arterial pressure are also discussed.
\end{abstract}

\section{Introduction}

For 60 years, the 'Goldblatt model' and its variants have been the mainstay of animal-based research on hypertension. The original Goldblatt model used dogs ${ }^{1}$ and they have remained a major source of experimental data on hypertension. Almost 100 years earlier, Richard Bright $(1836)^{2}$ noted the link between left ventricular hypertrophy and renal disease; he remarked on 'the frequency with which derangement of one organ is connected with the derangement of several others' but cautioned that 'we are not at liberty to assume that the disease of the kidney has been the primary cause on which the disease of the rest depended'. Measurement of arterial pressure dates back to the early 1730 s and the famous experiments of the Reverend Stephen Hales on horses; he also made observations on canine arterial pressure. ${ }^{3}$ But we need to go back

Correspondence: Professor A.R. Mitchell, B.Sc., B.Vet.Med., Ph.D., M.R.C.V.S., Department of Large Animal Medicine and Surgery, Royal Veterinary College, University of London, Hawkshead Lane, North Mymms, Hatfield, Herts AL9 7TA, UK.

This paper is based on a talk given to the European Medical Research Group on 24 February 1994. nearly another 2000 years to China to encounter the first statement of the suspicion that there is a link between renal disease, salt intake and hypertension.

'When the pulse is full and hard . . . the illness dominates the kidneys and has its seat therein.' 'If large amounts of salt are taken, the pulse will stiffen or harden'. ${ }^{4}$

The purpose of this review is to explore these issues and, in particular, the insights which may be gained from comparative medicine. Two receive special emphasis:

1. The importance of a perspective based on nutritional requirement and its magnitude in a range of species in judging clinical arguments about salt intake or experimental designs related to hypertension or renal physiology.

2. The importance of the detailed study of real disease, as it actually arises in various species, not just of surgically or pharmacologically contrived models, as the basis of comparative medicine. Thus, while dogs may readily be induced to become hypertensive, their real interest may lie in the fact that, despite this susceptibility, they may actually be rather 
resistant to both hypertension and its effects. If so, the reasons for this resistance offer potentially invaluable insights into the basis of hypertension. ${ }^{5}$ Similarly, the value of the dog in understanding the factors influencing the progression of chronic renal failure (CRF) may lie not in the consequences of $7 / 8$ or $15 / 16$ nephrectomy, but in the careful study of dogs with spontaneous renal failure, particularly where there is a familial susceptibility.

When the opportunities for the creation of new experimental models have been so powerfully enhanced by biotechnology, it is necessary, rather than perverse, to offer a reminder that models are a valuable part of comparative medicine, as they are in most branches of biomedical science, but they are only a part. Comparative medicine is not simply the conceit that one species can be contrived, by artefact, to serve as a model for the diseases of another: its essence lies in the insights and the questions arising from detailed study of the variety of the manifestations of ostensibly similar diseases in different species. In particular, the contrasts may be as informative as the similarities, whereas in models they may simply appear as shortcomings.

\section{Hypertension: what does it mean?}

Hypertension is like being 7 feet tall; it means that you are statistically unusual, not necessarily that you are ill; attempts to make you 'normal' may be more harmful than the actual condition. There are thus two possible definitions of hypertension:

1. The statistical level at which arterial pressure is abnormal.

2. The clinical level at which therapeutic intervention is justified.

The latter is clearly the more contentious. It depends on the individual, the possible causes of their higher pressure, their age and general health, the cost and acceptability of the proposed intervention and the ever-changing evidence on the effectiveness of particular prophylactic or therapeutic strategies.

There is, however, a clear distinction between arterial pressure and height, which is insufficiently appreciated: height is relatively constant, at least in the early decades of adult life, whereas pressure is not. Naturally, physiology textbooks emphasize the constancy of arterial pressure, since it is a prime example of homeostasis and its underlying negative feedback regulation. These are most obvious in the short-term control, for example, by baroreceptor reflexes, but also in the more subtle long-term control of arterial pressure by the kidney; this depends on the sensitivity of pressure natriuresis to increased arterial pressure. ${ }^{6}$ Control system theory naturally makes students focus on the maintenance of the 'set point' value for arterial pressure.

$\therefore$. . it is necessary that the arterial pressure remains constant or nearly constant because with a variable pressure one would never know whether dilating the blood vessels would necessarily increase the local blood flow. Fortunately, the circulation has an intricate system for regulation of the arterial pressure."

All students appreciate that in reality arterial pressure fluctuates between systolic and diastolic within each cardiac cycle, and that the best reflection of tissue perfusion may relate to mean arterial pressure. This is not half way between systolic and diastolic, but the average throughout the cardiac cycle; it is, therefore, closer to diastolic since systole is shorter. At high heart rates, however, when there is encroachment on the duration of diastole rather than systole, it rises. It is therefore important to realize that mean arterial pressure (and, to a lesser extent, diastolic pressure) is directly affected by heart rate. The primary determinants of arterial pressure are cardiac output, arterial compliance and arteriolar ('peripheral') resistance, and also the effects of reflected pressure waves. $^{8,9}$

\section{Variability of blood pressure}

'The force of the blood in its vessels is continually varying, according to ... the various distances of time after taking food . . . also from exercise, rest, different states of vigour or vivacity of the animal and many other circumstances' (Hales, 1733). ${ }^{3}$

With the increasing use of chronic noninvasive measurements of arterial pressure, it becomes clear that arterial pressure is far from stable. Apart from diurnal variation (or its clinical disturbances) and changes associated with respiration, posture, activity or apprehension, or occasionally with baroreflex failure, ${ }^{10-12}$ there is much more shortterm fluctuation than most of us have assumed, ${ }^{13,14}$ though the reasons may differ between species. ${ }^{15}$ It makes one wonder how repeated measurements on different occasions ever reach a reproducible level in individual subjects, yet they do, both in people and dogs; readings may vary but individuals tend to retain the same rank order. ${ }^{16-18}$ Perhaps the stereotyped routine of taking the measurement actually diminishes the short-term variability; it seems a question worth examining.

'White-coat' hypertension ${ }^{19,20}$ is a well-recognized phenomenon (fall in successive readings or the mean of readings on successive occasions attributed to decreasing apprehension as the technique becomes familiar); the question is, does the baseline level or the elevated level offer the greater insight into the patient's condition. ${ }^{21}$ White-coat 
hypertension is less marked in dogs $;{ }^{22}$ perhaps they only have the innocuous procedure, rather than its implications, to 'worry' about.

These considerations may seem mundane but they are absolutely central to any discussion about what constitutes normality of arterial pressure, and which departures from normality should arouse clinical concern: the range of diurnal variation? ${ }^{23}$ The peak or the duration of the nocturnal trough $^{20,24}$ or diurnal rise ${ }^{25}$ The extremes of the short-term fluctuation, including those caused by stress or activity, ${ }^{16,26,27}$ their duration or their frequency, ${ }^{28}$ or variability in itself? ${ }^{29}$ Systolic or diastolic hypertension? $?^{30-33}$ Or is mean arterial pressure helpful because it involves rate as well as pressure; mechanical damage akin to structural fatigue relates to the frequency as well as the size of the deformation. ${ }^{8.32}$ Recent evidence suggests that daily sodium excretion may relate more closely to the variability of arterial pressure than to its absolute level. ${ }^{34}$ At the very least, all sources of biological variation broaden the normal range, ${ }^{35}$ unless we can allow for their effect on individual subjects (for example, using specific normal ranges reflecting age, sex and ethnic background). There is thus the risk of Type 2 error (false negatives) with a heightened possibility of stroke or cardiac disease, or Type 1 error (false positives) and a possible lifetime exposure to expensive drugs and their side effects - often trivial to the clinical status of patients but devastating to their well-being. ${ }^{36}$ Among diagnostic devices, the sphygmomanometer is second only to the clinical thermometer in its familiarity, yet, on a different time scale, the difficulty of interpreting spot results is as great as that of drawing far-reaching conclusions from the exposure of a particular rock above the sea at a particular minute on a particular day.

Not all the problems stem from biological variation; instrumental variation arises from technical shortcomings but also from the different principles of measurement employed. There is a general grasp that indirect measurements can only be approximations and that direct measurements offer a 'gold standard'. To do so, they must use appropriate catheters and transducers. ${ }^{8,37,38}$ Even then, we cannot expect perfect comparisons with indirect techniques because these involve readings at different sites (hence different effects of reflected waves), different arteries and, almost inevitably, taken during different cardiac cycles. ${ }^{37.39,40}$

There is, therefore, very much more to a clinical diagnosis of hypertension than a reading above $140 / 90 \mathrm{mmHg}$ or whatever definition is currently favoured. Moreover, since the real concern is not the pressure but the harm that it may or may not do, even 'high' values within the normal range may occasion concern in some patients. For example, diabetics have glomerular capillaries that are exposed to higher pressure by the defective tone of renal afferent arterioles, hence lesser degrees of hypertension are potentially more damaging. ${ }^{41}$ Dogs, supposedly, seldom get diabetic nephropathy. ${ }^{42}$ Perhaps it is because the duration of their disease is too short - but canine models of diabetes show renal lesions ${ }^{43-45}$ and they also show reduced afferent arteriolar tone $;^{46}$ recent evidence suggests that at least some dogs with spontaneous diabetes do become proteinuric. ${ }^{47}$ Since the prevalence of canine hypertension is $l o w^{48}$ but diabetes is fairly common, dogs may offer useful insights into the link between hypertension and diabetic nephropathy, because it should be easier to separate those with diabetes, hypertension or both. Perhaps the low prevalence of hypertension makes it less likely that diabetic dogs sustain renal damage. If so, what about those breeds with naturally high arterial pressures ${ }^{48}$ is diabetes more likely to damage their kidneys and, if not, what protects them?

We shall return to the question of canine hypertension and what it may tell us about links with renal disease, but first we need to consider an area where data from a much broader range of species illustrate the value of a comparative approach, namely the controversy over salt and hypertension.

\section{Salt and hypertension}

There has been great interest in the regulatory role of salt appetite in animals. Two mysteries remain pre-eminent; what factors regulate it and why, even if need increases, does routine intake vastly exceed it. ${ }^{49}$ No one doubts that humans take more salt than they need; the issue is whether it matters. The debate is often religious rather than scientific, based upon belief in self-evident truths rather than hypotheses that are sufficiently flexible and strong to accommodate the data. ${ }^{50}$ What seems remarkable is the often grudging acceptance of benefit, ${ }^{51}$ even when it is conceded: 'Dietary salt restriction may improve the capacities of many anti-hypertensive medications to lower blood pressure and to increase withdrawal from medication in a portion of the patient population. However, one must avoid generalizations ... responses ... seem to vary ...' [italics added]. A variable response to therapy is not unique to salt restriction; variable or not, such responses seem well worth pursuing, subject to suitable precautions. Many have voiced their views on these matters and continue to do so without reaching a consensus. ${ }^{51-56}$ My views have also appeared elsewhere, ${ }^{49,57,58}$ and my purpose here is simply to emphasize how they differ and why this arises from an awareness of sodium regulation in a range of mammals.

Broadly, there are two kinds of evidence linking 
human sodium intake to hypertension; chronic, cross-cultural studies and acute intervention studies. The latter seek to demonstrate a hypotensive effect of short-term reductions of sodium intake either in normal or hypertensive subjects. Alternatively, they seek a hypertensive effect of sudden 'salt binges'. While these two approaches have different strengths and weaknesses, ${ }^{59}$ it is essential to realize that they address different questions. If normal salt intake provides a generous excess and therapeutic measures include natriuretic drugs, it can only make sense to moderate intake (even though some diuretics also have vascular effects). The more important issue is the prophylactic benefit, if it exists, of a sustained exposure to less dietary salt; early (even in utero) effects may be particularly important in determining the effectiveness of reductions in salt intake (as well as the intensity of the adult appetite for salt). ${ }^{60-62}$ This is much more contentious because it involves large populations and large industries; the former not only have to benefit but to have sufficient confidence in the benefit to exercise their consumer choice. Even then, however, they face the difficulty that they can only exercise choice over the minority of their sodium intake unless they considerably restrict the range of foods that they eat. That is because discretionary salt, added by the cook or at the table, is small compared with the salt added during food processing. . $^{50,56,63,64}$ The nub of the argument, therefore, is the need to reduce the latter in order to restore consumer choice for those who do accept a link between salt and hypertension. The rest are not, as sometimes represented, forced into an insipid and dangerous lifestyle based upon low salt consumption; no one has suggested a ban on salt cellars. . $^{50,58,59,65}$

The most persuasive evidence of a link between salt and human hypertension comes from crosscultural studies. There are few examples of highsalt cultures that avoid a high prevalence of hypertension, strokes, etc.; even some of these are dubious. ${ }^{59}$ There are, however, no exceptions to the rule that low-salt cultures not only have an enviably low, often negligible, prevalence of hypertension, but they avoid the age-related rise of arterial pressure, which even our insurers regard as normal. ${ }^{59}$ Part of the increase is due to reduced arterial compliance, which accelerates the rise in systolic pressure, moderates the rise in diastolic pressure and leaves mean pressure unaffected. ${ }^{66}$

Among the Cook Islanders of Polynesia, those who consume $60 \mathrm{mmol} /$ day have no hypertension and no age-related rise of blood pressure; those consuming $120 \mathrm{mmol} /$ day do and a third become hypertensive ${ }^{67}$ Data from China indicate that even where features of lifestyle such as low alcohol intake may maintain a low blood pressure among younger adults, the age-related rise associated with high salt intake obliterates this advantage beyond 50 years. ${ }^{68}$ Many hypertensives would have delayed or avoided the need for therapy ${ }^{69,70}$ if, somehow, they could have avoided the rise attributed to age, that is, subtracted it from the value at which their hypertension was diagnosed. Indeed, a useful definition of the high extreme of nutritional sodium requirement might be the highest level of chronic intake that avoids an age-related rise in pressure. ${ }^{71}$ Interestingly, dogs have a customary intake, which, like humans, is far above requirement ${ }^{59}$ and their arterial pressure rises with age, but they have a low prevalence of hypertension. ${ }^{48}$ This accords with evidence that they also resist the effects of salt loading unless, perhaps, it is combined with stress $^{5,59}$ or obesity. ${ }^{72,73}$ Insulin resistance and the resulting hyperinsulinaemia predispose to sodium retention, for example, in obesity.$^{74}$ Dogs, however, are resistant to hyperinsulinaemia as a cause of hypertension in a variety of situations including reduced renal mass, salt loading and obesity. ${ }^{75}$

A serious problem with much of the discussion in this controversy is the lack of objectivity in categorizing particular intakes as 'high' or 'low'; above all, without the perspective of the likely magnitude of sodium requirement, failure to appreciate the exorbitance of some sodium intakes. ${ }^{71,76}$ This bedevils the design and interpretation of experiments in both animals and humans, including even 'Intersalt'. $5,76,77$

\section{How much sodium is 'high'?}

A review of mammalian sodium requirement suggests that it is unlikely to exceed $0.6 \mathrm{mmol} / \mathrm{kg} /$ day; whether derived factorially or empirically, this is probably an overestimate. ${ }^{71,77}$ Those who concede this but advocate that humans, uniquely, have a higher requirement, also imply something that they probably would not accept, namely that human kidneys are exceptionally inept in their ability to conserve sodium. ${ }^{76}$ Those who seem unaware of $i^{51}$ continue to agonise over the effectiveness or otherwise of reducing intake to double the requirement from quadruple the requirement (70 from $160 \mathrm{mmol} /$ day $)$, let alone higher levels $(250 \mathrm{mmol} /$ day). It should be emphasized that these discussions concern maintenance requirement, that is, for a healthy adult, neither pregnant nor lactating. ${ }^{71}$ This provides the best basis for comparison because growth rates, pregnancy and lactation differ greatly between species.

Once these figures are grasped, we realize that a 'Western' intake of $300 \mathrm{mmol} / \mathrm{day}$ would be $4 \mathrm{mmol} / \mathrm{kg} / \mathrm{day}$ - similar to the customary intake in dogs. ${ }^{59}$ We also realize that the widely used 'normal' $1 \%$ salt diet of the rat represents $700-800$ $\mathrm{mmol} /$ day in a human $(11 \mathrm{mmol} / \mathrm{kg} /$ day $)$; far from 
being normal, such animals are likely to be chronically volume expanded with increased glomerular filtration rates and losses of other solutes, notably divalent ions, caused by chronic natriuresis. ${ }^{57,77}$ Indeed, were they human, these rats would have nearly double the intake associated with a $40 \%$ prevalence of hypertension in Northern Japan. ${ }^{77,78} \mathrm{We}$ also realize that experimental dogs, used to test hypotheses concerning the cardiovascular effects of sodium, are frequently on 'low' intakes, which are arguably normal, and 'high' intakes, which are simply preposterous. ${ }^{76}$ This is particularly unfortunate since important cardiovascular variables such as blood volume are especially sensitive to changes in sodium intake around or somewhat above requirement (0.6-2.6 $\mathrm{mmol} / \mathrm{kg} /$ day). ${ }^{79}$ Often the sodium intake is not even specified, that is, the experiment is essentially unrepeatable; extraordinarily this is even often true of reputable publications on renal physiology, which is so sensitive to changes in sodium intake. Thus glomerular filtration rate (GFR), genetic expression of renin and angiotensinogen, distal delivery of tubular fluid (and proximal reabsorption) are all sensitive to dietary sodium. ${ }^{80-82}$ Above all, we realize that the analysis of the 'Intersalt' data, in discarding the 'atypically low' populations, actually removed those whose sodium intake was closest to requirement. ${ }^{71,76}$ Calcium, as well as sodium, is implicated in the pathogenesis of hypertension ${ }^{83-86}$ and another important effect of excess salt intake may therefore be the associated increase in divalent ion excretion ${ }^{87}$ by raising parathyroid hormone secretion and therefore increasing the calcium concentration of arteriolar smooth muscle. Effects of sodium on catecholamine secretion may also contribute to hypertension. ${ }^{88}$

Much of the opposition to a reduction in customary sodium intake relates to hypothetical dangers or those facing small minorities, for example, victims of acute renal failure ${ }^{58.89}$ Frequently, the evidence of risk is based on data substantially below requirement. ${ }^{59,76,90,91}$ It is hard to resist the evidence, particularly that from the meta-analyses of Law and others ${ }^{53-55}$ and from McGregor and others $^{76.92-98}$ despite persisting opposition; ${ }^{52,99,100}$ it points to a link, for many though not necessarily all patients, between their chronic ingestion of excess sodium and their hypertension. ${ }^{76}$ Most remarkable is the fact that many observers struggle towards the concept that there may be a 'threshold' for an effect on pressure (in the range $50-100 \mathrm{mmol} / \mathrm{day}^{51}$ ) without appreciating that this may actually reflect the level at which intake exceeds nutritional requirement. The conclusion of the National Kidney Foundation publication on nonpharmacological management of hypertension ${ }^{101}$ is that the data are 'imperfect but nevertheless com- pelling'; the advice of the American Food and Nutrition Board is that a sodium intake of $5-22 \mathrm{mmol} /$ day $\quad(0.1-0.3 \mathrm{mmol} / \mathrm{kg} /$ day $)$ is reasonable. ${ }^{102}$

Finally, since this concerns comparative medicine, we must return to the archetypal model animal, and see what we might learn from hypertension and chronic renal failure (CRF) in dogs.

\section{Canine hypertension and CRF}

The literature on spontaneous canine hypertension is unsatisfactory, consisting mainly of small studies of selected populations, often using direct arterial measurements in conscious dogs. These inevitably tend to exaggerate the prevalence of elevated pressure ${ }^{103} \mathrm{Katz}$ and others (1939) ${ }^{104}$ warned that 'A single determination of the blood pressure of untrained dogs, with or without the use of morphine, does not appear to give the correct control blood pressure level'.... Some of the discrepancies of early work in this field were due to the use of general anaesthesia or of untrained dogs when anaesthesia was not employed.' They obtained indirect pressures averaging $132 \pm 12 / 85 \pm 8( \pm$ s.d.) in trained dogs, within the range that we observe in our epidemiological study of some 2,000 pet dogs. ${ }^{48}$ The earliest direct pressure measurements in dogs are those of Hales reported in 1733 with a mean of $112 \pm 9 \mathrm{mmHg}$ (56.6 inches of blood \pm s.e.m.) in the carotid arteries of 16 animals (from 3.6 to $23.6 \mathrm{~kg}$ ). ${ }^{3}$

An astonishingly patient study that involved screening 1,000 dogs found only $0.9 \%$ with a trained direct mean pressure above 'normal' $(145 \pm 8) .{ }^{105}$ This suggested a low prevalence of essential hypertension but is coloured by the effect of direct measurements (that is, elevation of both pressure and variability). Greyhounds have higher pressures than other dogs, associated with a higher cardiac index, a lower peripheral resistance (perhaps due to a lower collagen:elastin ratio) and differences in baroreceptor function. ${ }^{106,107}$ Bodey's observations during our epidemiological study indicate that the difference in normal pressure is inherent in the breed, regardless of whether it is trained for competition. Apart from any interpretation concerning hypertension, it is ironic that so much of the 'classical' cardiovascular physiology in experimental dogs should be based on such an atypical breed.

Essential hypertension is rare in dogs ${ }^{103,108}$ but a particular breed line has a substantial prevalence and offers a very useful experimental model. ${ }^{13}$ There is also a very useful canine model of spontaneous glomerulopathy in a breed line of Samoyeds. ${ }^{109}$ A low prevalence of essential 
hypertension might simply be a matter of genetics; with the increasing use of molecular biology to analyse the genetics of essential hypertension, ${ }^{110,111}$ this conclusion should eventually be testable.

If we believe that dogs are resistant to hypertension, CRF offers an important test of the hypothesis. In humans with chronic renal disease (glomerulonephritis), hypertension tends to begin early, while renal function is relatively well preserved; ${ }^{112}$ moreover, in this study, onset of hypertension followed the recognition of renal disease in $51 \%$ of hypertensive patients and preceded it in only $3 \%$; overall, $61 \%$ of these renal patients were hypertensive. Assuming that a GFR of $125 \mathrm{ml} /$ minute corresponds approximately to $100 \%$ GFR and that a plasma creatinine concentration of $2.5 \mathrm{mg} / \mathrm{dl}$ corresponds to $33 \%$ GFR in humans, ${ }^{113}$ dogs should show a $55 \%$ prevalence of hypertension at this level of renal function if they were similarly susceptible. Our early findings suggest that dogs have a low prevalence of hypertension even when GFR has declined. ${ }^{48,114}$

Interestingly, an early study of hypertensive mongrel dogs, three spontaneous and the rest Goldblatt models, noted no decline in renal function among the former and in only 4/7 of the latter. ${ }^{115}$ These studies covered periods of hypertension up to 3 years but the comparisons were with normotensive dogs rather than prehypertensive renal function; moreover all the pressures are high (probably because of direct arterial measurements in conscious dogs). Nevertheless, the authors concluded that it is apparent from these data that canine chronic benign blood pressure does not result in any progressive impairment of renal function'. If this conclusion is sustained, it will be important to discover the basis of their resistance. Equally, knowledge that normal dogs include breeds with average systolic pressure (for example, $151 \pm 21$ s.e.m. in Deerhounds ${ }^{48}$ ) in a range that would be regarded as borderline hypertensive in humans, ${ }^{33}$ let alone many individuals with pressures close to $200 \mathrm{mmHg}$, raises further important questions: many of these are athletic breeds - are the high pressures adaptive or maladaptive? Are these models of essential hypertension? Either way, why do these pressures not seem to cause harm, especially to renal and cardiovascular function? In addition, it should be possible to monitor young animals as they mature and look at the relationship between arterial pressure and left ventricular thickness. ${ }^{116}$ While it is widely assumed that hypertension causes the ventricular hypertrophy, there is some evidence to suggest that the latter can occur first, ${ }^{117,118}$ indeed, a recent study showed that the majority of patients with left ventricular hypertrophy were normotensive. ${ }^{119}$ Blood viscosity may be a key determinant of ventricular hypertrophy ${ }^{120}$ and so may sodium intake. ${ }^{121,122}$ The effect of hypertension may depend on wave reflection rather than pressure per se. ${ }^{123} \mathrm{~A}$ study of canine hypertension, using direct measurements, noted modest increases of pressure with renal disease but found no relationship with left ventricular hypertrophy. ${ }^{124}$

Canine renal failure offers an opportunity not only to test hypotheses concerning hypertension but also those concerning nutritional or therapeutic strategies for reducing the rate of progression of kidney disease. ${ }^{125}$ This hinges on the availability of techniques based on Tc-DTPA disappearance, which combine sufficient precision for serial monitoring of GFR with clinical acceptability in veterinary patients. ${ }^{126}$ It may be increasingly important to study spontaneous models of CRF rather than acute surgical, pharmacological or immunological renal trauma. These models often fail to produce a self-sustaining decline in GFR, ${ }^{127}$ whether or not they cause lesions or proteinuria; moreover, the crux of renal disease may be the cumulative effect of a lifetime of varied renal insults. ${ }^{125}$

Recently it has become clear, both from models and human patients, that a key determinant of self-sustaining progression may be the severity of the loss of renal mass. ${ }^{125,128}$ The initial appeal of the concept that adaptive hyperfiltration was also ultimately the cause of self-sustaining progression was that it separated the initiating causes (often remote in time and unknown) from the factors sustaining progression. The latter seemed more amenable to research and to clinical management. Even when hyperfiltration was superseded by other factors, including glomerular hypertension, as the likely basis of progression, ${ }^{129}$ the concept of selfperpetuating progression (and the subtotal nephrectomy and other models that sustained it) retained its appeal as a focus for research: it was, after all, the phenomenon that governed most of the clinical course of chronic renal disease. If it depends on extreme loss of nephrons it comes to represent, instead, a terminal feature of CRF, equivalent perhaps to the factors which finally stop the heart in chronic heart failure. ${ }^{125}$

\section{Conclusion}

There would seem to be great potential benefits from comparative medicine as the study of real disease in non-human patients, rather than the more restrictive sense of contriving animal models. Humans are certainly different but we should not assume that they are unique: to do so undermines our understanding of data obtained in man, let alone the insights available from other mammals, both in health and disease. 


\section{Acknowledgements}

I thank Rosemary Forster for preparing this manuscript, Angela Bodey and Allison Gleadhill for their contribu-

\section{References}

1. Goldblatt, H.E., Lynch, J., Hanzal, F. \& Summerville, W.W. The production of persistent elevation of systolic blood pressure by means of renal ischemia. J Exp Med 1934 , 59: $347-378$

2. Bright. $R$. Tabular view of the morbid appearances in one hundred cases connected with albuminous urine with observations. Guy's Hosp Rep 1836, 1: 380-400.

3. Hales, S. Statistical Essays, Vol. II: Haemostatics, Experiments VII \& VIII. Royal Society, London, 1733, pp. 31-47.

4. Shunyu, I. \& Huang Ti Nei Ching Su Wen (100-200 BC), cited by Swales, J.D. Sodium Metabolism in Disease. LloydLuke, London, 1975, p. 1.

5. Michell, A.R. Sodium in health and disease; what can we learn from animals? In: Michell, A.R. (ed.) The Advancement of Veterinary Science, Vol. 4: Grow'th Points and Comparative Medicine. CAB International, Wallingford, 1993, pp .171-184.

6. Guyton, A.C. Long-term arterial pressure control: an analysis from animal experiments and computer and graphic models. Am J Physiol 1990, 259: R865-877.

7. Guyton, A.C. Textbook of Medical Physiology, 7th edn. Saunders, Philadelphia, 1986, p. 244.

8. McDonald, D.A. In: Nichols, W.M. \& O'Rourke, M.F. (eds) Blood Flow in Arteries, 3rd edn. Edward Arnold, London, 1990, pp. 22-49; 143-269; 398-437.

9. Nichols, W.M., Avoho, A.P., Kelly, R.P.\& O'Rourke, M.F. Effects of age and of hypertension on wave travel and reflection. In: O'Rourke, M.F., Safar, M.E. \& Dzai, V.J. (eds) Arterial Vasodilatation: Mechanisms and Therapy. Edward Arnold, London, 1993, pp. 22-40.

10. Jamieson, M.J., Webster, J., Phillips, S. et al. The measurement of blood pressure; sitting or supine, once or twice? J Hypertens 1990, 8: 635-640.

11. Pickering. T.G. Characterization of blood pressure variations with ambulatory monitoring. In: O'Brien, E. \& O'Malley, K. (eds) Handbook of Hypertension, Vol. 14: Blood Pressure Measurement. Elsevier, Amsterdam, 1991, pp. 218-243.

12. Robertson, D., Hollister, A.S., Biaggioni, I.. Netterville, J.L., Mosqueda-Garcia, R. \& Robertson, R.M. The diagnosis and treatment of baroreceptor failure. $N$ Engl J Med 1993, 329: 1449-1455.

13. Bovee, K.C. Genetic essential hypertension in dogs: a new animal model. In: Michell, A.R. (ed.) The Advancement of Veterinary Science, Vol. 4: Veterinary Science - Growth Points and Comparative Medicine. CAB International, Wallingford. 1993, pp. 185-194.

14. Lossius, K.. Eriksen, M. \& Walloe, L. Fluctuations in blood flow to acral skin in humans: connections with heart rate and blood pressure variability. J Physiol 1993, 460: 641-655.

15. Toska, K. \& Erikson, M. Respiration-synchronous fluctuations in stroke volume, heart rate and arterial pressure in humans. $J$ Phy siol 1993, 472: 501-512.

16. Mahoney, L.T. \& Lauer, R.M. Consistency of blood pressure levels in children. Sem Nephrol 1989, 9: 230-235.

17. Hansen, H.S., Hyldebrandt, N., Rokkedal Nielsen, J. \& Froberg. K. Blood pressure distribution in a school-age population aged $8-10$ years: the Odense schoolchild study. $J$ Hypertens 1990, 8: 641-646.

18. Bodey, A.R., Manfield, N. \& Michell, A.R. Long-term stability of indirect measurements of arterial pressure in individual dogs. (In preparation). tions to our current research on hypertension and renal disease in dogs, and Waltham and Hills for supporting it.

19. O'Brien, E., Cox, J. \& O'Malley, K. Ambulatory blood pressure measurement in the evaluation of antihypertensive drug effect. In: O'Brien, E. \& O'Malley, K. (eds) Handbook of Hypertension, Vol. 14: Blood Pressure Measurement. Elsevier, Amsterdam, 1991, pp. 245-260.

20. Pickering, T.G. Ambulatory blood pressure monitoring in clinical practice: uses and abuses. In: Andrews, V.E. \& Fine L.G. (eds) International Yearbook of Nephrology. SpringerVerlag, London, 1993, pp. 55-65.

21. Julius, S., Mejia, A., Jones, K. et al. 'White coat' versus sustained borderline hypertension in Tecumseh, Michigan Hypertension, 16: 617-623.

22. Vincent, I.C., Michell, A.R. \& Leahy, R.A. Non-invasive measurement of arterial pressure in dogs: a potential indicator for the identification of stress. Res Vet Sci 1993, 54: 196-202.

23. Zachariah, P.K. \& Sumner, W.E. The clinical utility of blood pressure load in hypertension. Am J Hypertens 1993, 6: $194 \mathrm{~S}-197 \mathrm{~S}$.

24. Hassan, M.O., Al Shafie, O.T. \& Johnston, W.J. Loss of the nocturnal dip and increased variability of blood pressure in normotensive patients with non insulin-dependent diabetes mellitus. Clin Physiol 1993, 13: 519-523.

25. Mancia, G., Brunner, H.R., Conway, J. et al. What blood pressure to measure? J Hypertens 1991, 9 (Suppl. 6): S412-S418.

26. Anderson, D.E. Interactions of stress, salt and blood pressure. Ann Rev Physiol 1984, 46: 143-153.

27. Baba, S., Ozawa, H., Nakamoto, Y., Ueshima, H. \& Omae, T. Enhanced blood pressure response to regular daily stress in urban hypertensive men. $J$ Hypertens 1990, 8: 647-655.

28. Stanton, A. \& O'Brien, E. Non-invasive 24-hour ambulatory blood pressure monitoring: current status. Postgrad Med J 1993, 69: 255-267.

29. Frattola, A., Parati, G., Cuspidi, C., Albini, F. \& Mancia, G. Prognostic value of 24 -hour blood pressure variability. $J$ Hypertens 1993, 11: 1133-1137.

30. Bulpitt, C.J. Is systolic pressure more important than diastolic pressure? J Human Hypertens 1990, 4: 471-476.

31. Bruce, N.G., Wannamethee, G. \& Shaper, A.G. Lifestyle factors associated with geographic blood pressure variations among men and women in the UK. J Human Hypertens 1993, 7: 229-238.

32. Gallagher, D.E. \& O'Rourke, M.F. What is arterial pressure? In: O'Rourke, M.F., Safar, M.E. \& Dzai, V.J. (eds) Arterial Vasodilatation: Mechanisms and Therapy. Edward Arnold, London, 1993, pp. 134-148.

33. Sagie, A., Larson, M.G. \& Levy, D. The natural history of borderline isolated systolic hypertension. $N$ Engl J Med 1993, 329: 1912-1917.

34. Ruddy, M.C., Arora, A., Malka, E.S. \& Bialy, G.R. Blood pressure variability and urinary electrolyte excretion in normotensive adults. Am J Hypertens 1993, 6: 480-486.

35. Perry, I.J. \& Beevers, D.G. Measurement of blood pressure in epidemiological surveys. In: O'Brien, E. \& O'Malley, K. (eds) Handbook of Hypertension, Vol. 14: Blood Pressure Measurement. Elsevier, Amsterdam, 1991, pp. 174-183.

36. Anon. Trials and tribulations of a symptom-free hypertensive physician receiving the best of care. Lancet 1977, 2: 291-292. 
37. Raftery, E.B. Technical aspects of blood pressure measurement. In: O'Brien, E. \& O'Malley, K. (eds) Handbook of Hypertension, Vol. 14: Blood Pressure Measurement. Elsevier, Amsterdam, 1991, pp. 55-71.

38. Sykes, M.K., Vickers, M.D. \& Hull, C.J. Direct measurement of intravascular pressure. Chap. 13. In: Principles of Measurement and Monitoring in Anaesthesia and Intensive Care. Blackwell Scientific Publications, Oxford, 1991, pp. 163-174.

39. Waeber, B., Hayoz, D., Burnier, M., Nussberger, J. \& Brunner, H.R. Official standards and recommendations: a critical comment. In: O'Brien, E. \& O'Malley, K. (eds) Handbook of Hypertension, Vol. 14: Blood Pressure Measurement. Elsevier, Amsterdam, 1991, pp. 371-379.

40. Schwan, A. \& Jonsson, D. Short-term variation in blood pressure determines the accuracy of simultaneous and sequential recordings in the validation of blood pressure measuring devices. J Human Hypertens 1993, 7: 315-319.

41. Miles, A.M. \& Friedman, E.A. Strategies for slowing progression of diabetic nephropathy. In: Andrews, V.E. \& Fine, L.G. (eds) International Yearbook of Nephrology. Springer-Verlag, London, 1993, pp. 109-139.

42. Nelson, R.W. In: Ettinger, S.J. (ed.) Textbook of Veterinary Internal Medicine, 3rd edn. Chap. 96, Disorders of the endocrine pancreas. W.B. Saunders, Philadelphia, 1989. p. 1700.

43. del Castillo, E., Fuenzalida, R. \& Uranga, J. Increased glomerular filtration rate and glomerulopressin activity in diabetic dogs. Horm Metab Res 1977, 9: 46-53.

44. Kern, T.S. \& Engerman, R.L. Arrest of glomerulonephropathy in diabetic dogs by improved glycaemic control. Diabetologia 1990, 33: 522-525.

45. Whiteside, C., Katz, A., Cho, C. \& Silverman, M. Effect of unilateral nephrectomy in the diabetic dog. Clin Invest Med 1990, 13: 280-286.

46. Brown, S.A., Walton, C.L., Crawford, P. \& Bakris, G.L. Long-term effects of antihypertensive regimen on renal hemodynamics and proteinuria. Kidney Int 1993, 43: 1210-1217.

47. Kirsch, M. \& Reusch, C. Urine characteristics in dogs with diabetes mellitus: is there a diabetic nephropathy in the dog (in German)? Tierarztl-Prax 1993, 21: 345-348.

48. Michell, A.R. \& Bodey, A.R. Canine hypertension. Proceedings, American College of Veterinary Internal Medicine, Lakewood, Colorado, June 1994, pp. 502-505.

49. Michell, A.R. What is the importance of salt appetite? Perspect Biol Med (in press).

50. Michel, A.R. Sums and assumptions about salt. Perspect Biol Med 1984, 27: 221-233.

51. Muntzel, M. \& Drueke, T. A comprehensive review of the salt and blood pressure relationship. Am J Hypertens 1992, 5: $1 S-42 S$.

52. Swales, J.D. Dietary salt and blood pressure: the role of meta-analyses. J Hypertens 1991, 9 (Suppl. 6): S47-S49.

53. Law, M.R., Frost, C.D. \& Wald, N.J. By how much does dietary salt reduction lower blood pressure? I. Analysis of observational data among populations. Br Med J 1991, 302: $811-815$

54. Frost, C.D., Law, M.R. \& Wald, N.J. By how much does dietary salt reduction lower blood pressure? II. Analysis of observational data within populations. Br Med J 1991, 302: 815-818.

55. Law, M.R., Frost, C.D. \& Wald, N.J. By how much does dietary salt reduction lower blood pressure? III. Analysis of data from trials of salt reduction. $\mathrm{Br} \mathrm{Med} J$ 1991, 302: 819-824.

56. Stamler, J. Dietary salt and blood pressure. Ann NY Acad Sci 1993, 676: 122-156.

57. Michell, A.R. Salt appetite, salt intake and hypertension: a deviation of perspective. Perspect Biol Med 1978, 21 335-347.

58. Michell, A.R. Salt and hypertension. Lancet 1984, 2: 634.
59. Michell, A.R. Salt intake, animal health and hypertension should sleeping dogs lie? In: Rivers, J. \& Burger, I. (eds) Recent Advances in Dog and Cat Nutrition. Cambridge University Press, Cambridge, 1989, pp. 275-292.

60. Dahl, L.K. Salt and hypertension. Am J Clin Nutr 1972, 25: 231-244.

61. Di Nicolantonio, R., Spargo, S. \& Morgan, T.O. Prenatal high salt diet increases blood pressure and salt retention in the spontaneously hypertensive rat. Clin Exp Pharmacol Physiol 1987, 14: 233-235.

62. Contreras, R.J. Differences in perinatal $\mathrm{NaCl}$ exposure alter blood pressure levels of adult rats. Am J Physiol 1989, 25: R70-R77.

63. Sanchez-Castillo, S.P., Warrender, S., Whitehead, T.P. \& James, W.P.T. An assessment of the sources of dietary salt in a British population. Clin Sci 1987, 72: 95-102.

64. Elmer, P.J., Grimm, R.H., Flack, J. \& Laing, B. Dietary sodium reduction for hypertension prevention and treatment. Hypertension 1991, 17 (Suppl. I): I182-I189.

65. Michell, A.R. Salt and hypertension. Lancet 1980, 1: 1358.

66. Hilden, $T$. The influence of arterial compliance on diastolic blood pressure and its relation to cardiovascular events. $J$ Human Hypertens 1991, 5: 131-135.

67. Norton, S.A. Salt consumption in ancient Polynesia. Perspect Biol Med 1992, 35: 160-181.

68. Stamler, E., Liu, L.S., Nichols, R. et al. Blood pressure and life style in the People's Republic of China: three samples in the Intersalt study. J Human Hypertens 1993, 7: 429-435.

69. Beard, T.C. Hypertension after Intersalt: prospects for prevention. J Cardiovasc Pharmacol 1990, 16: S31-S34.

70. Beard, T.C. A salt-hypertension hypothesis. J Cardiovasc Pharmcol 1990, 16: S35-S38.

71. Michell, A.R. Physiological aspects of the requirement for sodium in mammals. Nutr Res Rev 1989, 2: 149-160.

72. West, D.B., Wehberg, K.E., Kieswetter, K. \& Granger, J.P. Blunted natriuretic response to an acute sodium load in obese hypertensive dogs. Hypertension 1992, 19 (Suppl. I): 196-I100.

73. Granger, J.P., West, D. \& Scott, J. Abnormal pressure natriuresis in the dog model of obesity-induced hypertension. Hypertension 1994, 23 (Suppl. I): I8-I11.

74. Shimamoto, K., Hirata, A., Fukuoka, M., Higashiura, K., Miyazaki, Y. \& Shiiki, M. Insulin sensitivity and the effects of insulin on renal sodium handling and pressure systems in essential hypertensive patients. Hypertension 1994, 23 (Suppl. I): 129-I33.

75. Hall, J.E., Brands, H.W., Hildebrandt, D.A. \& Mizelle, H.L. Obesity-associated hypertension: hyperinsulinaemia and renal mechanisms. Hypertension 1992, 19: I45-I55.

76. Michell, A.R. The comparative clinical nutrition of sodium intake: lessons from animals. Br J Nutr Med (in press).

77. Michell, A.R. The Clinical Biology of Mammalian Sodium Metabolism. Pergamon, Oxford (in press).

78. Denton, D.A. The Hunger for Salt. Springer-Verlag, Berlin, 1982, pp. 580-594.

79. Linden, R.J., Mary, D.A.S.G. \& Nickalls, R. The relationship between blood volume and dietary salt in the dog. $J$ Physiol 1982, 330: 66P.

80. Roos, J.C., Koomans, H.A., Mees, E.J.D. \& Delawi, I.M.K Renal sodium handling in normal humans subjected to low, normal and extremely high sodium supplies. Am J Physiol 1985, 249F: 941-947.

81. Simpson, F.O. Sodium intake, body sodium and sodium excretion. Lancet 1988, 1: 25-28.

82. Benabe, J.E. \& Martinez-Maldonado, M. Dietary modification of the renin angiotensin system. Sem Nephrol 1993, 13: $567-572$.

83. Blaustein, M.P. Sodium ions, calcium ions, blood pressure and hypertension; a reassessment and a hypothesis. $\mathrm{Am} \mathrm{J}$ Physiol 1977, 232: C165-C173.

84. Haddy, F.J. Ionic control of vascular smooth muscle cells. Kidney Int 1988, 34 (Suppl 25): S2-S8. 
85. De Wardener, H.E. The primary role of the kidney and salt intake in the aetiology of essential hypertension. Clin $\mathrm{Sci}$ 1990, 79: 193-200, 289-297.

86. McCarron, D.A., Morris, C.D., Young, E., Roullet, C. \& Drueke, T. Dietary calcium and blood pressure: modifying factors in specific populations. Am J Clin Nutr 1991, 54 (Suppl 1): 215S-219S.

87. McGregor, G.A. \& Capuccio, F.P. The kidney and essential hypertension: a link to osteoporosis? J Hypertens 1993, 11: $781-785$.

88. Gill, J.R., Gullner, H.G., Lake, C.R. \& Lakatua, D.J. Plasma and urinary catecholamines in salt-sensitive idiopathic hypertension. Hypertension 1988, 11: 312-319.

89. De Wardener, H.E. \& Kaplan, N.M. On the assertion that a moderate restriction of sodium intake may have adverse health effects. Am J Hypertens 1993, 6: 810-814.

90. Ott, C.E., Welch, W.J. \& Lorenz, J.N. Effect of salt deprivation on blood pressure in rats. Am J Physiol 1989, 256: H1426-H1431.

91. Ruppert, M., Diehl, J. \& Kolloch, R. Dietary sodium restriction increases serum total and LDL-cholesterol in salt sensitive and salt resistant normotensive adults. $J$ Hypertens 1990, 8 (Suppl 3): 24S.

92. McGregor, G.A., Markandu, N.D., Sagnella, G.A., Singer, D.R.J. \& Cappuccio, F.P. Double-blind study of three sodium intakes and long term effects of sodium restriction in essential hypertension. Lancet 1989, 2: 1244-1247.

93. Stamler, R. Implications of the Intersalt study. Hypertension 1991, 17 (Suppl. I): I16-I20.

94. Elliott, P. Observational studies of salt and blood pressure. Hypertension 1991, 17 (Suppl I): I3-I8.

95. Law, M.R., Frost, C.D. \& Wald, N.J. Dietary salt and blood pressure. J Hypertens 1991, 9 (Suppl 6): S37-S41.

96. McGregor, G.A. Dietary salt and blood pressure. Lancet 1994, 343: 545.

97. Beard, T.C. Dietary salt and blood pressure. Lancet 1994, 343: 546.

98. Meervaala, E. \& Karppanen, H. Dietary salt and blood pressure. Lancet 1994, 343: 545.

99. Swales, D. Studies of salt intake in hypertension: what can epidemiology teach us? Am J Hypertens 1990, 3: 645-649.

100. Drueke, T.B. False certitudes on salt and blood pressure. Lancet 1994, 343: 61.

101. Anderson, S. Hypertension: Nonpharmacologic Management. National Kidney Foundation, New York, 1993.

102. Ernst, N.D. Health promotion roles of the Federal Government and food industry in nutrition and blood pressure. Hypertension 1991, 17 (Suppl I): I196-I200.

103. Michell, A.R. Hypertension in companion animals. In Raw, M.-E. \& Parkinson, T.J. (eds) The Veterinary Animal. Blackwell Scientific Publications, Oxford, 1993, pp. 11-23.

104. Katz, L.N., Friedman, M., Rodbard, S. \& Weinstein, W Observations on the genesis of renal hypertension. Am Heart $J$ 1939, 17: 334-356.

105. Katz, J.I., Skom, J.H. \& Wakerlin, G.E. Pathogenesis of spontaneous and pyelonephritic hypertension in the dog. Circ Res 1957, 5: 137-143.

106. Fischer, G.M. Cox, R.H. \& Detweiler, D.K. Altered arterial connective tissue in racing greyhound dogs. Experientia 1975, 31: 1426-1427.

107. Cox, R.H., Bagshaw, R.J. \& Detweiler, D.K. Baroreceptor reflex cardiovascular control in mongrel dogs and racing greyhounds. Am J Physiol 1985, 249: H655-H662.

108. Bovee, K.C. Current status of hypertension in the dog. In: Soklowski, J.H. \& Campfield, W.W. (eds) 16th Annual Waltham/OSU Symposium (Nephrology and Urology). Ka Kan Foods Inc., Vernon, CA, 1992, pp. 17-22.

109. Valli, V.E.O., Baumal, R., Thorner, P. et al. Dietary modification reduces splitting of glomerular basement membranes and delays death due to renal failure in canine X-linked hereditary nephritis. Lab Invest 1991, 65: 67-73.
110. St Lezin, E.M. \& Kurtz, T.W. The renin gene and hypertension. Sem Nephrol 1993, 13: 581-585.

111. Soubrier, F., Wei, L., Hubert, C., Clauser, E., Alhenc-Gelas, F. \& Curvol, P. Molecular biology of the angiotensin I converting enzyme: II. Structure-function; gene polymorphism and clinical implications. J Hypertens 1993, 11: 599-604.

112. Danielsen, H., Kornerup, H.J., Olsen, S. \& Posborg, V. Arterial hypertension in chronic glomerulonephritis. An analysis of 310 cases. Clin Nephrol 1983, 19: 284-287.

113. Alfrey, A.C. Chronic renal failure: manifestations and pathogenesis. In: Schrier, R.W. (ed.) Renal and Electrolyte Disorders. Little Brown, Boston, 1976, pp. 319-347.

114. Michell, A.R. \& Gleadhill, A. Clinical renal failure in dogs as a model for human renal disease. J Am Soc Nephrol 1993, 4: 776.

115. Stamler, J., Katz, L.N. \& Robbard, S. Serial renal clearances in dogs with nephrogenic and spontaneous hypertension. $J$ Exp Med 1949, 90: 511-524.

116. Bodey, A.R., Brownlie, S.E. \& Michell, A.R. Left ventricular pressure and arterial pressure in dogs. (in preparation).

117. Devereux, R.B. \& Pickering, T.G. Ambulatory blood pressure in assessing the cardiac impact and prognosis of hypertension. In: O'Brien, E. \& O'Malley, K. (eds) Handbook of Hypertension, Vol. 14: Blood Pressure Measurement. Elsevier, Amsterdam, 1991, pp. 261-286.

118. Schmeider, R.E. \& Messerli, F.H. Is the decrease in arterial pressure the sole factor for reduction of left ventricular hypertrophy? Am J Med 1992, 92 (Suppl 4B): 28S-34S.

119. Schunkert, H., Hense, H.-W., Holmes, S.R. et al. Association between a deletion polymorphism of the angiotensinconverting enzyme gene and left ventricular hypertrophy. $N$ Engl J Med 1994, 330: 1634-1638.

120. Devereux, R.B., Drayer, J.I.M., Chien, S. et al. Whole blood viscosity as a determinant of cardiac hypertrophy in systemic hypertension. Am J Cardiol 1984, 54: 592-595.

121. Daniels, S.D., Meyer, R.A. \& Loggie, J.M.H. Determinants of cardiac involvement in children and adolescents with essential hypertension. Circulation 1990, 82: 1243-1248.

122. Harmsen, E. \& Leenen, F.H. Dietary sodium induced cardiac hypertrophy. Can J Physiol Pharmacol 1992, 70: 580-586.

123. Yaginuma, T. \& O'Rourke, M. Modification of wave travel and reflection by vasodilator therapy. In: O'Rourke, M.F., Safar, M.E. \& Dzai, V.J. (eds) Arterial Vasodilatation: Mechanisms and Therapy. Edward Arnold, London, 1993, pp. 50-61.

124. Valtonen, M.H. \& Oksanen, A. Cardiovascular disease and nephritis in dogs. J Small Anim Pract 1993, 13: 687-697.

125. Michell, A.R. Progression of chronic renal failure: have we progressed? In: Raw, M.E. \& Parkinson, T.J. (eds) Veterinary Annual, Vol. 35. Blackwell Scientific Publications, Oxford, 1995 (in press).

126. Gleadhill, A., Peters, A.M. \& Michell, A.R. A simple, minimally invasive and clinically acceptable method of measuring glomerular filtration rate in dogs. Res $\mathrm{Vet} \mathrm{Sci}$ 1994 (in press)

127. Viberti, G.C., Walker, J.D. \& Pinto, J. Diabetic nephropathy. In: Alberti, K.T.M.M., De Fronzo, R.A., Keen, H. \& Zimmet, P. (eds) International Textbook of Diabetes Mellitus, Vol. 2. Wiley, Chichester, 1992, pp. 1267-1328.

128. Fine, L.G. How little kidney tissue is enough? $N$ Engl J Med 1991, 32: 1097-1099.

129. Castellino, P., Shonat, J. \& De Fronzo, R.A. Hyperfiltration and diabetic nephropathy: is it the beginning? or is it the end? Sem Nephrol 1990, 10: 228-241. 